Article

\title{
On the Primary Water Radicals' Production in the Presence of Gold Nanoparticles: Electron Pulse Radiolysis Study
}

\author{
Viacheslav Shcherbakov (D), Sergey A. Denisov *(D) and Mehran Mostafavi * \\ Institute de Chimie Physique (ICP), CNRS/Université Paris-Saclay, Bât. 349, 91405 Orsay, France; \\ viacheslav.shcherbakov@universite-paris-saclay.fr \\ * Correspondence: sergey.denisov@universite-paris-saclay.fr (S.A.D.); \\ mehran.mostafavi@universite-paris-saclay.fr (M.M.)
}

Received: 19 November 2020; Accepted: 8 December 2020; Published: 10 December 2020

\begin{abstract}
Gold nanoparticles are known to cause a radiosensitizing effect, which is a promising way to improve radiation therapy. However, the radiosensitization mechanism is not yet fully understood. It is currently assumed that gold nanoparticles can influence various physical, chemical, and biological processes. Pulse radiolysis is a powerful tool that can examine one of the proposed effects of gold nanoparticles, such as increased free radical production. In this work, we shed light on the consequence of ionizing radiation interaction with gold nanoparticles by direct measurements of solvated electrons using the pulse radiolysis technique. We found that at a therapeutically relevant gold concentration $\left(<3 \mathrm{mM}\right.$ atomic gold, $\left.<600 \mu \mathrm{g} \times \mathrm{cm}^{-3}\right)$, the presence of gold nanoparticles in solution does not induce higher primary radicals' formation. This result contradicts some hypotheses about free radical formation in the presence of gold nanoparticles under ionizing radiation previously reported in the literature.
\end{abstract}

Keywords: radiosensitization; radicals; gold nanoparticles; radiolysis

\section{Introduction}

Ionizing radiation is part of numerous health applications in diagnostics and therapeutics. Radio treatment (RT) is used in an overwhelming number of cases along with other cancer-fighting methods: surgery, chemotherapy, and immunotherapy. RT's main development challenge is to reduce side effects, which is addressed by better dose localization and attempts to decrease the required dose by utilizing special radiosensitizing agents. The radiosensitizers could be drugs, macromolecules, oxygen and its mimics, or high Z-materials, including gold nanoparticles (AuNPs) [1]. AuNPs are desirable material for bioapplications due to their facile synthesis, small size, versatile surface chemistry, easy cell membrane penetration properties, and low toxicity [2].

First experiments on gold as a dose enhancer were done using foils [3]. This study was focusing on the interface effects occurring between high- $Z$ material and cell monolayer under $\mathrm{X}$-ray radiation. The next step was to utilize higher surface area materials such as microparticles. Gold microspheres $(1.5-3 \mu \mathrm{m}$, up to $3 \mathrm{wt} \%)$ were used for curing tumors in mice. The radiosensitizing effect was attributed to a physical dose enhancement, which was verified by Fricke dosimetry. The dose enhancement effect was present only for X-ray ionizing radiation, but not for $\gamma$-rays $\left({ }^{137} \mathrm{Cs}\right)$ [4]. Later the nanoparticles of gold were used for radiosensitization studies [5]. This seminal work provoked a cascade of studies on the radiosensitization effect using nanomaterials. The interest in this subject from the medical, radiation chemistry, and biology communities was growing since then for decades [6-9].

As discussed elsewhere $[8,10]$, the initially used hypothesis on dose enhancement due to higher cross-sections of high- $\mathrm{Z}$ materials towards ionizing radiation ( $\mathrm{X}$-rays range) compared to low- $\mathrm{Z}$ 
elements was unable to explain observed results. The problem is that the concentration of AuNPs in vivo and in vitro experiments is less than required to deposit a significant amount of energy into gold particles. In the early works [4,5], a much higher concentration $(0.3-3 \mathrm{wt} \%)$ of gold was used with a combination of X-rays. In more recent works, particles' delivery is targeted within the cell interior with much lower concentrations (ca. $100 \mu \mathrm{g} / \mathrm{mL}, 0.01 \mathrm{wt} \%$ ), utilizing different radiation sources such as $\gamma$-rays and protons, not only $\mathrm{X}$-rays [9]. However, the radiosensitizing effects, sometimes higher than 50\% [9], were observed in the presence of AuNPs even at a low gold concentration and ionizing radiation energy well above the $\mathrm{X}$-ray range, where the cross-section of gold and water or soft-tissue are alike [11]. The fact that the observed results did not correlate with the type of ionizing radiation and its energy urged scientists to look for other explanations. To date, the biological effects of gold nanoparticles are actively studied [7-9,12]. One of the observed effects in the presence of AuNPs under ionizing radiation is higher oxidative stress, which causes cell biochemistry disruption and death. These radiobiological effects are not easy to unravel due to cellular chemistry's complexity, including signal pathways responsible for the bystander effect $[13,14]$. The oxidative stress is often understood in the context of higher dose absorption, which causes a higher concentration of reactive species, mainly oxygen-containing (ROS), and the main focus is devoted to hydroxyl radical $\left(\bullet^{\circ} \mathrm{OH}\right)[6,9]$.

Interestingly, several experiments with molecular systems support the idea of increased free radicals production in the presence of AuNPs. The additional radical production was always higher than predicted by physical dose enhancement and was observed for different radiation types and a broad range of energies $[6,15,16]$. Therefore, other explanations were proposed, such as special properties of interfacial water leading to higher radiolytic yields of primary radicals; a higher concentration of oxygen-rich species on the surface of AuNPs, leading to higher ROS production [6].

Pulse radiolysis is a suitable technique for the direct detection of free radicals' overproduction in homogenous solutions. Therefore, in this work, we focus on the radiolysis of water in the presence of AuNPs. The firm conviction dictates the necessity of such work that the radiosensitization mechanism explanation complexity must be reduced. The development of pulse radiolysis techniques allows us to directly determine the radiolytic yield of hydrated electrons $\left(\mathrm{e}^{-}{ }_{\text {aq }}\right)$ precisely and indirectly that of ${ }^{\bullet} \mathrm{OH}$ radicals, just a few picoseconds after the energy deposition in water. Herein, we report the absence of AuNPs' effect on primary water radicals formation and discuss the value of these results on the explanation of the AuNPs' radiosensitizing effect.

\section{Materials and Methods}

\subsection{Electron Pulse Radiolysis}

The photocathode-driven electron accelerator ELYSE (University of Paris-Saclay) operating at $5 \mathrm{~Hz}$ delivering 5 ps electron pulses (45-100 Gy) at $7 \mathrm{MeV}$ was used in this study. The deposited dose per pulse was deduced from $\mathrm{e}^{-}$aq absorbance measurements in pure water and verified before each set of scans. More details on the experimental setup could be read elsewhere $[17,18]$. The stroboscopic detection with a mechanical delay line was used for time-resolved studies in the range of $10 \mathrm{~ns}$. For longer timescales, a transient absorption setup with a streak camera detection was used. For all experiments, the optical quartz cells of $5 \mathrm{~mm}$ length were used with thin $(100 \mu \mathrm{m})$ optical windows.

Optical detection during pulse radiolysis measurements of AuNP suspensions has some limitations. The gold nanoparticles suspensions strongly absorb in the UV-vis range. Thus, only the red light $>600 \mathrm{~nm}$ can penetrate the samples. The solutions of $30 \mathrm{~mL}$ were circulated using a peristaltic pump with a flow rate of $40 \mathrm{~mL} \times \mathrm{min}^{-1}$ for measurements in microsecond timescales, whereas, for subnanosecond scales, static quartz cells were used.

Utilizing pulse radiolysis coupled with time-resolved spectroscopy for AuNPs suspensions studies requires the correct reference, where pure water may not be a suitable one. The time evolution of radical species in AuNPs suspensions can be affected by the presence of nanoparticle stabilizers. Thus, a more relevant reference is a supernatant obtained by centrifugation of AuNPs suspension, 
eliminating gold nanoparticles to a large degree but leaving other chemical substances. We controlled by absorption measurement that at least $99 \%$ of AuNPs were removed from the supernatant solution (Figure S1). Although for picosecond and nanosecond timescales, where bimolecular reactions are not significant, pure water could be appropriate as a reference. Our experimental setup allows easily for the determination of optical density within 1 mO.D. accuracy for a nanosecond and shorter timescales, and 5 mO.D. for a microsecond one. Thus, the hydrated electron concentration could be determined with an accuracy of $50 \mathrm{nM}$ and $250 \mathrm{nM}$, respectively.

\subsection{Gold Nanoparticles Synthesis}

Gold nanoparticles were prepared by two widely known methods: reduction by sodium borohydride [19] and sodium citrate (Turkevich method) [20]. The final gold concentration was $3 \mathrm{mM}$ (atomic concentration) or $600 \mu \mathrm{g} / \mathrm{mL}$ in both cases. Reduction by sodium borohydride included the following steps: $3 \mathrm{~mL}$ of $100 \mathrm{mM}$ solution of $\mathrm{K}\left[\mathrm{AuCl}_{4}\right]$ was mixed with $87.7 \mathrm{~mL}$ of deionized water and $9.3 \mathrm{~mL}$ of $100 \mathrm{mM}$ solution of $\mathrm{NaBH}_{4}$ was added to the solution under stirring by magnet stir bar with high speed. After the reduction of gold ions, the solution changed color from yellow to dark red. After the borohydride was added, stirring was continued for $5 \mathrm{~min}$. For the Turkevich method, $3 \mathrm{~mL}$ of $100 \mathrm{mM}$ solution of $\mathrm{K}\left[\mathrm{AuCl}_{4}\right]$ was mixed with $82.5 \mathrm{~mL}$ of deionized water. The solution was heated up to $100{ }^{\circ} \mathrm{C}$, then $4.5 \mathrm{~mL}$ of $100 \mathrm{mM}$ of sodium citrate was added to the solution under stirring by magnet stir bar with high speed. When the solution has turned red, heating was stopped. The solution was cooled down under stirring. The full reduction of gold ions was verified by the total disappearance of the absorption at $220 \mathrm{~nm}$. All chemicals were purchased from Sigma-Aldrich (St. Quentin Fallavier, France).

The solution of AuNPs prepared by borohydride reduction method had $\mathrm{pH}$ 8. The solution of AuNPs prepared by citrate reduction method had $\mathrm{pH} 4$, which was adjusted by $\mathrm{NaOH}$ to 5.4. The UV-vis absorption spectra of AuNPs, their size distribution, zeta-potentials, and TEM image are presented in the Supporting Information (SI).

\section{Results and Discussion}

In the present work, two types of AuNPs were used prepared using borohydride and sodium citrate (Turkevich) as reduction agents. Both techniques allowed us to synthesis stable AuNPs with an atomic concentration of gold up to $3 \mathrm{mM}(600 \mu \mathrm{g} / \mathrm{mL})$ and with simplistic small molecule/ion stabilization. The size of particles synthesized by the borohydride reduction method was $20 \mathrm{~nm}$ (Figures S1A and S2, the absorption maximum was $520 \mathrm{~nm}$ and the zeta potential was $-20 \mathrm{mV}$ ). Those particles prepared by the Turkevich method had a mean hydrodynamic diameter of $45 \mathrm{~nm}$ (Figure S1B, the absorption maximum was $533 \mathrm{~nm}$ and the zeta potential was $-35 \mathrm{mV}$ ).

The radiolysis of water after energy deposition could undergo two pathways (Scheme 1). The main path was ionization, and the minor one was a dissociation of an excited water molecule. After ionization, the survived water-cation radical loses a proton, leaving behind ${ }^{\bullet} \mathrm{OH}$ radical [21]. A secondary electron thermalizes within a few femtoseconds, followed by its solvation within $1 \mathrm{ps.} \mathrm{Dissociation} \mathrm{of} \mathrm{the}$ excited water molecule leads to the formation of the ${ }^{\bullet} \mathrm{H}$ atom and ${ }^{\bullet} \mathrm{OH}$ radical. The formed species inside ionization spurs react with each other and solutes present in the solution. Besides, one must always remember that spurs tend to increase in volume due to radicals' diffusion, which decreases the possibility of such reactions. 


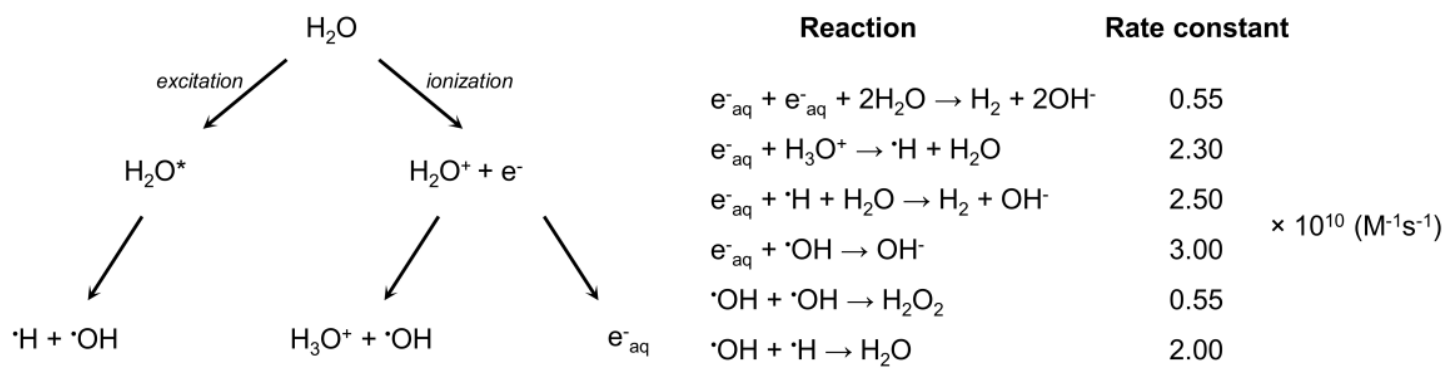

Scheme 1. First steps of water radiolysis within 1 ps and some reactions of hydrated electron $\left(\mathrm{e}^{-}{ }_{\text {aq }}\right)$ and hydroxyl radical $\left({ }^{\bullet} \mathrm{OH}\right)$ and their constant rates [22].

Direct detection is possible for the hydrated electron, which has a high molar absorption coefficient [23]. We found no difference in hydrated electrons production through picosecond pulse radiolysis in water and the solution of AuNPs (with the highest possible concentration for the measurements, $3 \mathrm{mM}$ ) on a time scale of a few tens of picoseconds, where radical-radical reactions did not occur (Figure 1 and Figures S5-S10). The hydrated electron concentration just after the 5 ps electron pulse correlates with $90 \%$ of ${ }^{\bullet} \mathrm{OH}$ radicals (ionization path, a yield of the hydrated electron at 10 ps was $0.44 \mu \mathrm{mol} / \mathrm{J}[24]$ and $\left.\bullet{ }^{\bullet} \mathrm{H} 0.52 \mu \mathrm{mol} / \mathrm{J}[21,24]\right)$.
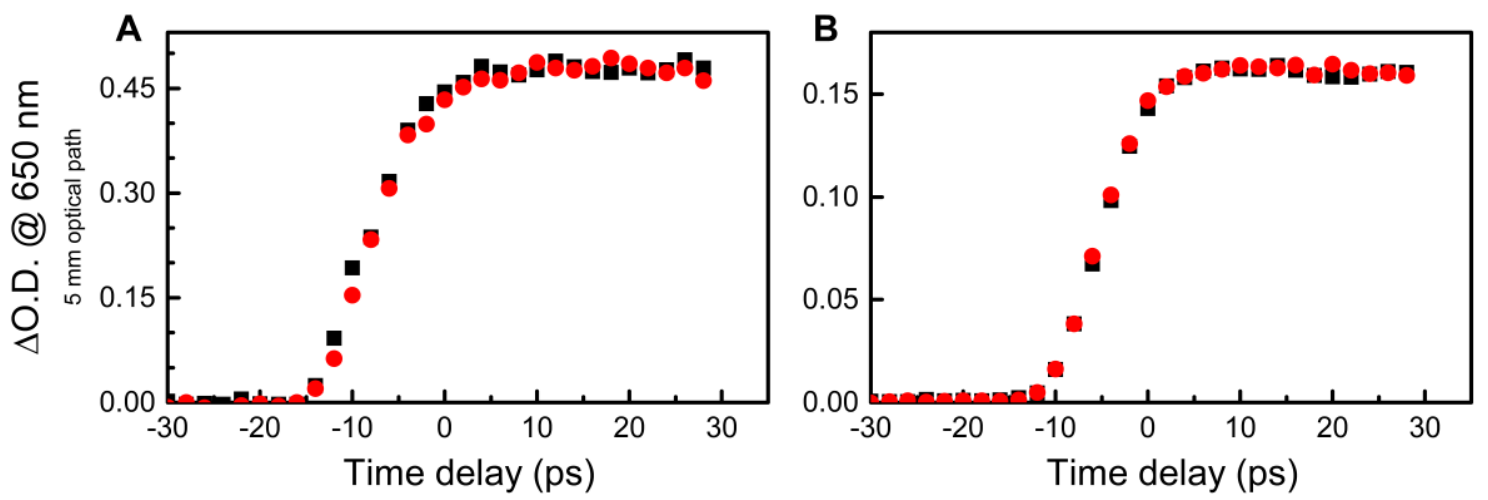

Figure 1. Kinetics of hydrated electrons within a time range of tens of picoseconds after a 5 ps electron pulse in water (black squares) and AuNPs suspensions containing $3 \mathrm{mM}$ of gold atoms (red dots) prepared by borohydride (A) and citrate (B) reduction methods.

One could claim that in the presence of AuNPs, the water dissociation channels could be altered due to the unique properties of interfacial water molecules, which could lead to higher ${ }^{\bullet} \mathrm{OH}$ and ${ }^{\bullet} \mathrm{H}$ production. This hypothesis came to be invalid because the decays of hydrated electrons on nanosecond and microsecond scales were not affected (Figures 2 and 3 and Figures S5-S10). This observation indicates that the radical-radical reactions occurred in the radiation track in the same way as in the solution without AuNPs (Scheme 1). 

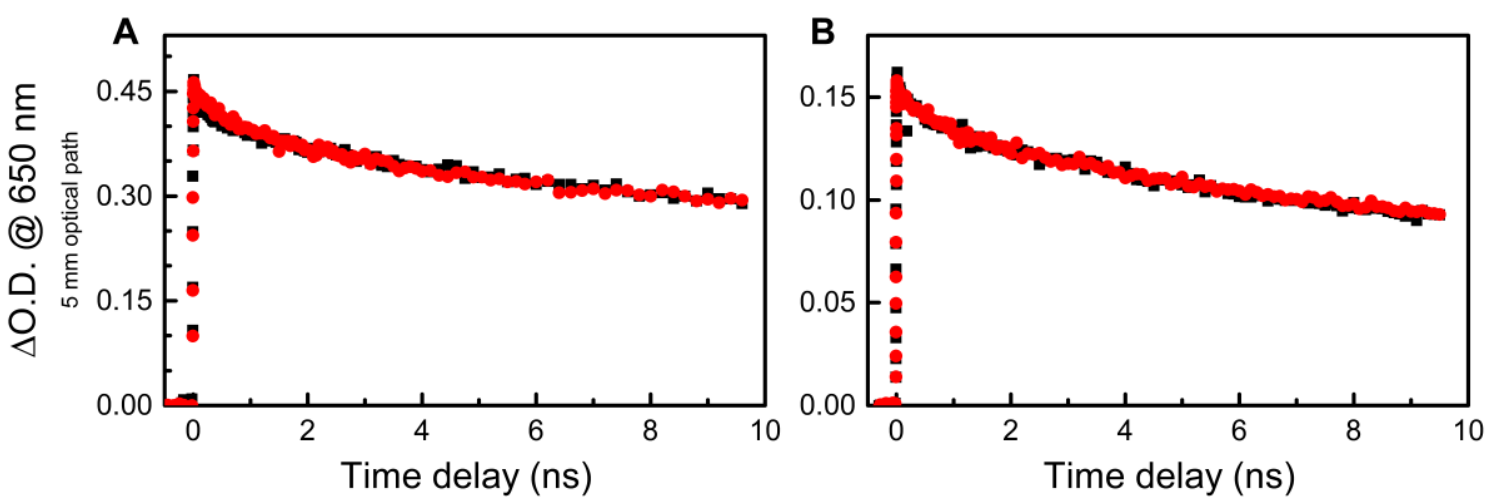

Figure 2. Kinetics of hydrated electrons within a few nanoseconds time range after a 5 ps electron pulse in water (black squares) and AuNPs suspensions containing $3 \mathrm{mM}$ of gold atoms (red dots) prepared by borohydride (A) and citrate (B) reduction methods.
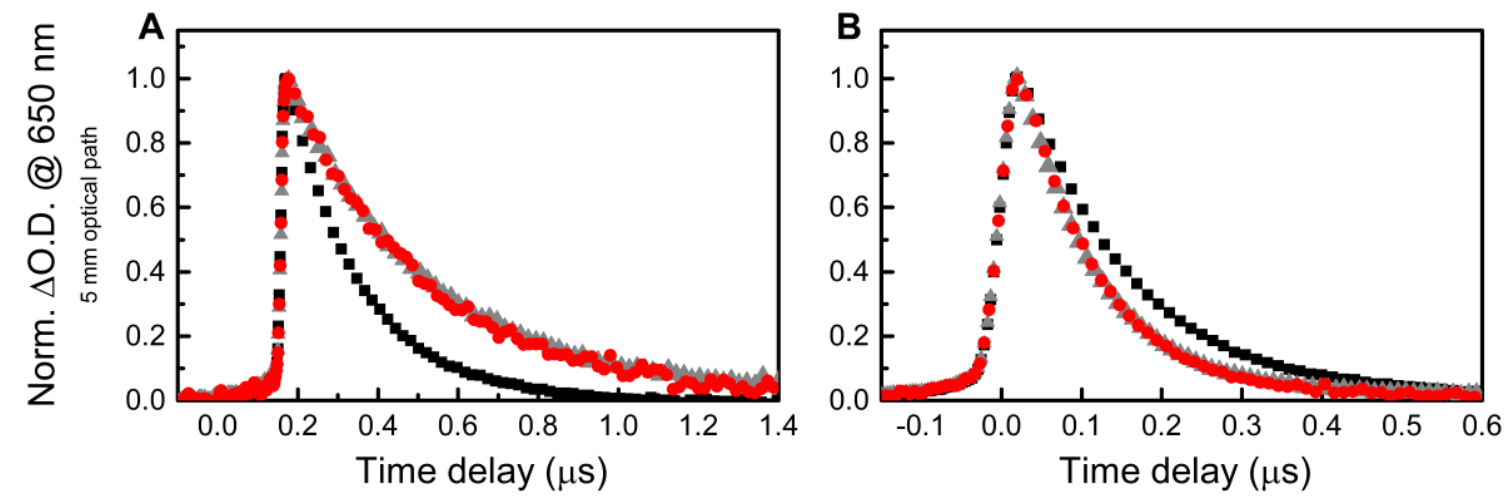

Figure 3. Kinetics of hydrated electrons within a microsecond time range after a 5 ps electron pulse in water (black squares), AuNPs suspensions containing $3 \mathrm{mM}$ of gold atoms (red dots), and their supernatants (grey triangle). (A) AuNPs were prepared by the borohydride reduction method. AuNPs suspension, its supernatant, and water had pH 8. (B) AuNPs were prepared by the Turkevich method. AuNPs suspension and its supernatant had $\mathrm{pH}$ 5.4, and water had $\mathrm{pH} 6$.

We selected supernatants as references for a microsecond range because they contained most of the solutes, which could react with $\mathrm{e}^{-}{ }_{\mathrm{s}}$ and/or ${ }^{\bullet} \mathrm{OH}$ radicals. In the case of AuNPs prepared by the borohydride reduction method, the decay of hydrated electrons was slower in AuNPs suspension and its supernatant than in neat water with the same $\mathrm{pH}$ (Figure 3A). It is explained by the fact that anions $\mathrm{BO}_{3}{ }^{3-}$ and $\mathrm{BH}_{4}{ }^{-}$react with the ${ }^{\bullet} \mathrm{OH}$ radical [25], suppressing the ${ }^{\bullet} \mathrm{OH}$ radical-hydrated electron interaction, which increases the lifetime of $\mathrm{e}^{-}$aq. In contrast to the AuNPs solution prepared by the Turkevich method, the decay in the supernatant and AuNPs suspension was faster than in water (Figure 3B) because hydrated electrons reacted with acetonedicarboxylic acid (DCA) generated during the synthesis as a byproduct of citrate oxidation [26]. Absorption at $260 \mathrm{~nm}$ in the supernatant verified the presence of DCA (Figure S1B). The rate constant of the hydrated electron reaction with DCA is expected to be similar to the acetone reaction $\left(6.5 \times 10^{9} \mathrm{M}^{-1} \mathrm{~s}^{-1}\right)$ [25]. This observation demonstrates the absence of any primary radical overproduction reported for similar AuNPs by indirect measurements $[6,15]$ or presolvated electron scavenging reported for a higher concentration of AuNPs stabilized by ionic liquids, by both muon methods and pulse radiolysis $[27,28]$. Previously the absence of $\bullet \mathrm{H}$ overproduction in the AuNPs solutions stabilized by ionic liquids was reported [28].

Similar experimental results, namely the absence of increased primary radicals' production studied by pulse-radiolysis, were obtained for silver nanoparticles (AgNPs). The experimental data, synthesis, and characterization methods for those samples are presented in the Supporting Materials (Figures S3 and S4). 
The conducted experiments were different from those in vitro and in vivo due to extreme dose rates, exceeding $10^{13} \mathrm{~Gy} / \mathrm{s}$. At such high dose rates, the lifetime of radicals was significantly reduced, e.g., the hydrated electrons were entirely disappearing within ca. $1 \mu$ s (Figure 3) due to a high concentration of later and ${ }^{\bullet} \mathrm{OH}$ radicals in the order of micromoles per liter. The concentration of AuNPs lay in the range of $12 \mathrm{nM}$, and thus the interaction between radicals and particles, which is discussed elsewhere $[29,30]$, was a statistically rare event in our conditions. Therefore, observed decays of hydrated electrons in the microsecond range were explained by radical chemistry mainly within the radicals' spurs and diffusion into the volume of the solution. If AuNPs cause higher dose absorption, then it must lead to a higher primary radicals' formation, which could eventually result in a higher concentration of ROS later in time. When ionizing radiation is applied, the higher production of secondary electrons occurs around AuNP compared to water. For X-ray radiation, the dose absorption is two orders of magnitude higher due to the higher cross-section for gold compared to water molecules. For $\gamma$ quants and high-energy particles, the increase of secondary electrons production occurs because those low energy electrons emitted from AuNP have higher LET values compared to those generated in water. Thus, more primary radicals are produced around single nanoparticles, no matter what kind of radiation is applied. To have a $10 \%$ difference in the absorbed dose between water and AuNPs suspension at X-ray energies where the cross-section of gold is the highest (35 keV) [31], the concentration of AuNPs must be in the order of $3 \mathrm{mM}$ of the atomic gold concentration. At the same concentration of gold under higher energy ionizing radiation, the dose absorbance enhancement will be in the order of $0.06 \%$. It is almost impossible to detect such a difference with direct or even more difficult for indirect measurements.

Of course, such a way of thinking is applicable only for homogenous solutions, and it is different for particles' aggregates usually formed in the cell. In many works, fluorescent dyes were used to detect ROS [6]. Some of these works report a 4.5 -fold enhancement of ${ }^{\bullet} \mathrm{OH}$ radical production even for $1.25 \mathrm{MeV}$ gamma rays, which have a similar linear energy transfer as $7 \mathrm{MeV}$ electrons used in our work [15]. In the fluorescent method, the sacrificial molecule is converted to a fluorescent molecule reacting with $\mathrm{ROS}$, such as the ${ }^{\bullet} \mathrm{OH}$ radical [32]. Our results contradicted the proposed explanations. Only the fluorescent molecule formation was measured in the works utilizing fluorescent dyes, while the initial molecule's disappearance was missed [6]. In our understanding, the authors misinterpret their experimental results since they did not consider gold nanoparticles' catalytic properties towards organic radicals formed under ionizing radiation [33-35], which could affect the fluorescent product's mechanism formation.

We would like to stress out that the results of this paper must be utilized with care for cellular systems, where local dose enhancement around the AuNP must be taken into account for the radiosensitization effect.

\section{Conclusions}

To conclude, it was shown that in the presence of $20 \mathrm{~nm}$ and $45 \mathrm{~nm}$ AuNPs and AgNPs at a therapeutical concentration ( $\leq 3 \mathrm{mM}$ atomic concentration) in homogeneous solutions under $5 \mathrm{ps}$ electron pulse $(7 \mathrm{MeV})$, there was no detectable increase of primary radicals' formation and as a result, another ROS production increase was not expected. In this way, to explain the effects of AuNPs under ionizing radiation such as radiosensitization requires other mechanisms than an increase of radiolysis yield of primary radicals. Such mechanisms of AuNPs' action must occur not at the timescale of energy deposition, primary radicals' formation, and their further evolution, but later in a homogeneous step of water radiolysis. This could be related to the chemical activity of gold nanoparticles, namely, catalysis. We will thoroughly analyze this subject in future work that is in progress.

Supplementary Materials: The following are available online at http://www.mdpi.com/2079-4991/10/12/2478/s1, Figure S1: Absorption spectra of AuNPs suspensions containing $3 \mathrm{mM}$ of gold atoms prepared by borohydride reduction method (red), and its supernatant (black) (A); Turkevich method (pink), and its supernatant (black) (B). Figure S2: Characterization of AuNPs prepared by borohydride reduction method. TEM image (A) and 
size distribution (B). Figure S3: Absorption spectra of AgNPs prepared by borohydride reduction method (A) and Turkevich method (B). Figure S4: Kinetics of hydrated electrons within microsecond time range after a 5 ps electron pulse in AgNPs suspensions containing $2 \mathrm{mM}$ of silver atoms (orange dots) and their supernatants (grey triangles). (A) AgNPs were prepared by the borohydride reduction method. (B) AgNPs were prepared by the Turkevich method. Figure S5: Kinetics of hydrated electrons within picosecond and nanosecond time ranges after a 5 ps electron pulse in water (black squares) and AuNPs suspension containing 2 mM of gold atoms prepared by borohydride reduction method $\left(\lambda_{\max }=518 \mathrm{~nm}\right.$; red dots). Figure S6: Kinetics of hydrated electrons within picosecond and nanosecond time ranges after a 5 ps electron pulse in water (black squares) and AuNPs suspension containing $2 \mathrm{mM}$ of gold atoms prepared by borohydride reduction method with $3 \mathrm{mM}$ of sodium citrate used as a surfactant $\left(\lambda_{\max }=517 \mathrm{~nm}\right.$; red dots). No effect of additional citrate $(3 \mathrm{mM}) \mathrm{was}$ observed. Figure S7: Kinetics of hydrated electrons within picosecond and nanosecond time ranges after a 5 ps electron pulse in water (black squares) and AuNPs suspension containing $2 \mathrm{mM}$ of gold atoms prepared by the Turkevich method (Au:citrate ratio is 1:1.5, $\lambda_{\max }=533 \mathrm{~nm}$; red dots). Figure S8: Kinetics of hydrated electrons within picosecond and nanosecond time ranges after a 5 ps electron pulse in water (black squares) and AuNPs suspension containing $1 \mathrm{mM}$ of gold atoms prepared by the Turkevich method (Au:citrate ratio is $1: 1.5, \lambda_{\max }=$ $533 \mathrm{~nm}$; red dots). Figure S9: Kinetics of hydrated electrons within picosecond and nanosecond time ranges after a 5 ps electron pulse in water (black squares) and AuNPs suspension containing $2 \mathrm{mM}$ of gold atoms prepared by the Turkevich method (Au:citrate ratio is 1:4, $\lambda_{\max }=520 \mathrm{~nm}$; red dots). Figure S10: Kinetics of hydrated electrons within picosecond and nanosecond time ranges after a 5 ps electron pulse in water (black squares) and AuNPs suspension containing $1 \mathrm{mM}$ of gold atoms prepared by the Turkevich method (Au:citrate ratio is 1:4, $\lambda_{\max }=520 \mathrm{~nm}$; red dots).

Author Contributions: Methodology, V.S., S.A.D., and M.M.; validation, V.S., S.A.D., and M.M.; formal analysis, V.S., S.A.D. and M.M.; investigation, V.S., and S.A.D.; data curation, V.S., and S.A.D.; writing-original draft preparation, V.S., S.A.D., and M.M.; writing—review and editing, V.S., S.A.D., and M.M.; supervision, S.A.D., and M.M.; project administration, S.A.D., and M.M.; funding acquisition, M.M. All authors have read and agreed to the published version of the manuscript.

Funding: Viacheslav Shcherbakov PhD grant has been received from Doctoral school (Ecole Doctorale 2MIB) of Paris-Saclay University.

Conflicts of Interest: The authors declare no conflict of interest.

\section{References}

1. Wang, H.; Mu, X.; He, H.; Zhang, X.D. Cancer Radiosensitizers. Trends Pharmacol. Sci. 2018, 39, $24-48$. [CrossRef] [PubMed]

2. Subiel, A.; Ashmore, R.; Schettino, G. Standards and methodologies for characterizing radiobiological impact of high-Z nanoparticles. Theranostics 2016, 6, 1651-1671. [CrossRef] [PubMed]

3. Regulla, D.F.; Hiebert, L.B.; Seidenbusch, M. Physical and Biological Interface Dose Effects in Tissue due to X-Ray- Induced Release of Secondary Radiation from Metallic Gold Surfaces. Radiat. Res. 1998, 150, 92-100. [CrossRef]

4. Herold, D.M.; Das, I.J.; Stobbe, C.C.; Iyer, R.V.; Chapman, J.D. Gold microspheres: A selective technique for producing biologically effective dose enhancement. Int. J. Radiat. Biol. 2000, 76, 1357-1364.

5. Hainfeld, J.F.; Slatkin, D.N.; Smilowitz, H.M. The use of gold nanoparticles to enhance radiotherapy in mice. Phys. Med. Biol. 2004, 49, N309. [CrossRef]

6. Howard, D.; Sebastian, S.; Le, Q.V.C.; Thierry, B.; Kempson, I. Chemical mechanisms of nanoparticle radiosensitization and radioprotection: A review of structure-function relationships influencing reactive oxygen species. Int. J. Mol. Sci. 2020, 21, 579. [CrossRef]

7. Rosa, S.; Connolly, C.; Schettino, G.; Butterworth, K.T.; Prise, K.M. Biological mechanisms of gold nanoparticle radiosensitization. Cancer Nanotechnol. 2017, 8. [CrossRef]

8. Butterworth, K.T.; McMahon, S.J.; Currell, F.J.; Prise, K.M. Physical basis and biological mechanisms of gold nanoparticle radiosensitization. Nanoscale 2012, 4, 4830-4838. [CrossRef]

9. Her, S.; Jaffray, D.A.; Allen, C. Gold nanoparticles for applications in cancer radiotherapy: Mechanisms and recent advancements. Adv. Drug Deliv. Rev. 2017, 109, 84-101. [CrossRef]

10. McMahon, S.J.; Hyland, W.B.; Brun, E.; Butterworth, K.T.; Coulter, J.A.; Douki, T.; Hirst, D.G.; Jain, S.; Kavanagh, A.P.; Krpetic, Z.; et al. Energy dependence of gold nanoparticle radiosensitization in plasmid DNA. J. Phys. Chem. C 2011, 115, 20160-20167. [CrossRef]

11. Hubbell, J.H.; Seltzer, S.M. Tables of X-Ray Mass Attenuation Coefficients and Mass Energy-Absorption Coefficients $1 \mathrm{keV}$ to $20 \mathrm{MeV}$ for Elements $Z=1$ to 92 and 48 Additional Substances of Dosimetric Interest; National Institute of Standards and Technology: Gaithersburg, MD, USA, 1995. 
12. Turnbull, T.; Douglass, M.; Williamson, N.H.; Howard, D.; Bhardwaj, R.; Lawrence, M.; Paterson, D.J.; Bezak, E.; Thierry, B.; Kempson, I.M. Cross-Correlative Single-Cell Analysis Reveals Biological Mechanisms of Nanoparticle Radiosensitization. ACS Nano 2019, 13, 5077-5090. [CrossRef] [PubMed]

13. Belyakov, O.V.; Mitchell, S.A.; Parikh, D.; Randers-Pehrson, G.; Marino, S.A.; Amundson, S.A.; Geard, C.R.; Brenner, D.J. Biological effects in unirradiated human tissue induced by radiation damage up to $1 \mathrm{~mm}$ away. Proc. Natl. Acad. Sci. USA 2005, 102, 14203-14208. [CrossRef] [PubMed]

14. Rodriguez-Ruiz, M.E.; Vitale, I.; Harrington, K.J.; Melero, I.; Galluzzi, L. Immunological impact of cell death signaling driven by radiation on the tumor microenvironment. Nat. Immunol. 2019. [CrossRef]

15. Gilles, M.; Brun, E.; Sicard-Roselli, C. Quantification of hydroxyl radicals and solvated electrons produced by irradiated gold nanoparticles suggests a crucial role of interfacial water. J. Colloid Interface Sci. 2018, 525, 31-38. [CrossRef] [PubMed]

16. Misawa, M.; Takahashi, J. Generation of reactive oxygen species induced by gold nanoparticles under X-ray and UV Irradiations. Nanomed. Nanotechnol. Biol. Med. 2011, 7, 604-614. [CrossRef] [PubMed]

17. Belloni, J.; Monard, H.; Gobert, F.; Larbre, J.P.; Demarque, A.; De Waele, V.; Lampre, I.; Marignier, J.L.; Mostafavi, M.; Bourdon, J.C.; et al. ELYSE-A picosecond electron accelerator for pulse radiolysis research. Nucl. Instruments Methods Phys. Res. Sect. A Accel. Spectrometers Detect. Assoc. Equip. 2005, 539, 527-539. [CrossRef]

18. Marignier, J.-L.; de Waele, V.; Monard, H.; Gobert, F.; Larbre, J.-P.; Demarque, A.; Mostafavi, M.; Belloni, J. Time-resolved spectroscopy at the picosecond laser-triggered electron accelerator ELYSE. Radiat. Phys. Chem. 2006, 75, 1024-1033. [CrossRef]

19. Deraedt, C.; Salmon, L.; Gatard, S.; Ciganda, R.; Hernandez, R.; Ruiz, J.; Astruc, D. Sodium borohydride stabilizes very active gold nanoparticle catalysts. Chem. Commun. 2014, 50, 14194-14196. [CrossRef]

20. Wuithschick, M.; Birnbaum, A.; Witte, S.; Sztucki, M.; Vainio, U.; Pinna, N.; Rademann, K.; Emmerling, F.; Kraehnert, R.; Polte, J. Turkevich in New Robes: Key Questions Answered for the Most Common Gold Nanoparticle Synthesis. ACS Nano 2015, 9, 7052-7071. [CrossRef]

21. Buxton, G. The Radiation Chemistry of Liquid Water. In Charge Particle and Photon Interactions with Matter; CRC Press: Boca Raton, FL, USA, 2003; pp. 333-363. ISBN 978-0-8247-4623-0.

22. Le Caër, $\mathrm{S}$. Water Radiolysis: Influence of Oxide Surfaces on $\mathrm{H}_{2}$ Production under Ionizing Radiation. Water 2011, 3, 235-253. [CrossRef]

23. Torche, F.; Marignier, J.L. Direct Evaluation of the Molar Absorption Coefficient of Hydrated Electron by the Isosbestic Point Method. J. Phys. Chem. B 2016, 120, 7201-7206. [CrossRef] [PubMed]

24. Wang, F.; Schmidhammer, U.; Larbre, J.-P.; Zong, Z.; Marignier, J.-L.; Mostafavi, M. Time-dependent yield of the hydrated electron and the hydroxyl radical in $\mathrm{D}_{2} \mathrm{O}$ : A picosecond pulse radiolysis study. Phys. Chem. Chem. Phys. 2018, 20, 15671-15679. [CrossRef] [PubMed]

25. Buxton, G.V.; Greenstock, C.L.; Helman, W.P.; Ross, A.B. Critical Review of rate constants for reactions of hydrated electrons, hydrogen atoms and hydroxyl radicals $\left(\mathrm{OH} / \mathrm{O}^{-}\right.$in Aqueous Solution. J. Phys. Chem. Ref. Data 1988, 17, 513-886. [CrossRef]

26. Al Gharib, S.; Marignier, J.L.; El Omar, A.K.; Naja, A.; Le Caer, S.; Mostafavi, M.; Belloni, J. Key Role of the Oxidized Citrate-Free Radical in the Nucleation Mechanism of the Metal Nanoparticle Turkevich Synthesis. J. Phys. Chem. C 2019, 123, 22624-22633. [CrossRef]

27. Ghandi, K.; Wang, F.; Landry, C. Mehran Mostafavi Naked Gold Nanoparticles and Hot Electrons in Water. Sci. Rep. 2018, 8, 7258-7264. [CrossRef]

28. Ghandi, K.; Findlater, A.D.; Mahimwalla, Z.; MacNeil, C.S.; Awoonor-Williams, E.; Zahariev, F.; Gordon, M.S. Ultra-fast electron capture by electrosterically-stabilized gold nanoparticles. Nanoscale 2015, 7, 11545-11551. [CrossRef]

29. Hermannsdörfer, J.; De Jonge, N.; Verch, A. Electron beam induced chemistry of gold nanoparticles in saline solution. Chem. Commun. 2015, 51, 16393-16396. [CrossRef]

30. Nowicka, A.M.; Hasse, U.; Hermes, M.; Scholz, F. Hydroxyl radicals attack metallic gold. Angew. Chem. Int. Ed. 2010, 49, 1061-1063. [CrossRef]

31. McMahon, S.J.; Paganetti, H.; Prise, K.M. Optimising element choice for nanoparticle radiosensitisers. Nanoscale 2016, 8, 581-589. [CrossRef]

32. Gomes, A.; Fernandes, E.; Lima, J.L.F.C. Fluorescence probes used for detection of reactive oxygen species. J. Biochem. Biophys. Methods 2005, 65, 45-80. [CrossRef] 
33. Meisel, D. Catalysis of Hydrogen Production in Irradiated Aqueous Solutions by Gold Sols. J. Am. Chem. Soc. 1979, 101, 6133-6135. [CrossRef]

34. Henglein, A. Reactions of organic free radicals at colloidal silver in aqueous solution. Electron pool effect and water decomposition. J. Phys. Chem. 1979, 83, 2209-2216. [CrossRef]

35. Zidki, T.; Cohen, H.; Meyerstein, D. Reactions of alkyl-radicals with gold and silver nanoparticles in aqueous solutions. Phys. Chem. Chem. Phys. 2006, 8, 3552-3556. [CrossRef] [PubMed]

Publisher's Note: MDPI stays neutral with regard to jurisdictional claims in published maps and institutional affiliations.

(C) 2020 by the authors. Licensee MDPI, Basel, Switzerland. This article is an open access article distributed under the terms and conditions of the Creative Commons Attribution (CC BY) license (http://creativecommons.org/licenses/by/4.0/). 